\title{
Erratum to: Characterization of carbonaceous aerosols at Mount Lu in South China: implication for secondary organic carbon formation and long-range transport
}

\author{
Peng-hui $\mathrm{Li}^{1} \cdot$ Yan Wang ${ }^{2} \cdot$ Tao $\mathrm{Li}^{2} \cdot$ Lei $\mathrm{Sun}^{2} \cdot{\mathrm{Xianliang} \mathrm{Yi}^{3} \cdot \mathrm{Li} \text {-qiong Guo }}^{4}$. \\ Rui-hong $\mathrm{Su}^{5}$
}

Published online: 26 June 2015

(C) Springer-Verlag Berlin Heidelberg 2015

Erratum to: Environ Sci Pollut Res

DOI 10.1007/s11356-015-4654-9

In the Acknowledgments section "National Natural Science Foundation of China (201177073, 41475115)" should be "National Natural Science Foundation of China (21177073, 41475115)"

The online version of the original article can be found at http://dx.doi.org/ 10.1007/s11356-015-4654-9.

\section{Peng-hui Li}

lipenghui406@163.com

$\triangle$ Yan Wang

wy@sdu.edu.cn; wy405@126.com

1 School of Environmental Science and Safety Engineering, Tianjin University of Technology, Tianjin 300384, China

2 School of Environmental Science and Engineering, Shandong University, Jinan 250100, China

3 School of Food and Environment, Dalian University of Technology, Panjin 124221, China

4 Department of Occupational \& Environmental Health, School of Public Health, Tianjin Medical University, Tianjin 300070, China

5 Shijiazhuang Integrated Geological Team, Shijiazhuang 050081, China 